\title{
Management of humeral shaft fracture: a comparative study between interlocking nail and dynamic compression plating
}

\author{
Golam Hashib*
}

Senior Registrar, Department of Orthopaedics, The Calcutta Medical Research Institute, Kolkata, West Bengal, India

Received: 07 May 2016

Accepted: 14 May 2016

*Correspondence:

Dr. Golam Hashib,

E-mail: rubin_1@ $@$ rediffmail.com

Copyright: ( $\subseteq$ the author(s), publisher and licensee Medip Academy. This is an open-access article distributed under the terms of the Creative Commons Attribution Non-Commercial License, which permits unrestricted non-commercial use, distribution, and reproduction in any medium, provided the original work is properly cited.

\section{ABSTRACT}

Background: Fractures of humeral shaft are commonly encountered by orthopaedic surgeons accounting for approximately $3 \%$ of all fractures. Treatment of these injuries continues to evolve as advances are made in both operative and non-operative management. Most humeral shaft fractures can be managed non-operatively with anticipated good to excellent results.

Methods: 29 cases with fracture of shaft of humerus were treated operatively in the Department of Orthopaedics, Katihar Medical College. Out of these, 15 cases (Group-A) underwent internal fixation by humeral interlocking nail and 14 cases (Group-B) underwent internal fixation by dynamic compression plating, with or without bone grafting. Bone grafting was done in 8 cases of Group-A and 5 cases of group-B.

Results: All cases, except one from each group returned to their previous occupation. Both these cases developed non-union. They were able to perform daily activities but not able to resume their occupation. Thus the functional result was good in $92.3 \%$ of cases and poor in $7.7 \%$ of cases of either group. 4 cases in group-B (30.8\%) managed by dynamic compression plating developed infections. In this study complications were also observed. Two of them were superficial infections that responded well to antibiotics and dressings and later healed well and united. Two cases developed discharging sinuses and subsequently infected union. Later the plate was removed and sinus tract excised. The sinus tract healed but left unsightly scar marks over the arm. Only one patient $(7.7 \%)$ of group-A developed deep seated infection and subsequent non-union. 3 cases of group-A $(23.1 \%)$ developed shortening ranging from $1.5 \mathrm{~cm}$ to $4 \mathrm{~cm}$. All these cases were cases of old non-union with sclerotic bone ends which had to be nibbled and refreshed. Shortening developed in 2 cases $(15.4 \%)$ of group-B. One non-union was seen in each group. While the screws of one dynamic compression $(7.7 \%)$ went loose, no implant failure occurred in interlocking nails. One case (7.7\%) of group-A developed axillary nerve injury, which might be attributed to the fact that the incision extended 6-7 $\mathrm{cm}$ beyond the acromion process. Only one case in group-B developed 10o angulation.

Conclusions: Dynamic compression plating has stood the test of time as an excellent method of stabilizing transverse diaphyseal fractures of humerus. The plate produces a compression at the fracture site promoting osteosynthesis. But the technique is not suitable for segmental fractures, pathological fractures, communited fractures, gross osteoporosis, non-union and fractures much proximal or distal to shaft. Introduction of interlocking nailing has largely solved problems faced by the standard dynamic compression plating technique. An advantage of humerus interlocking is that even when non-union developed daily activities could be performed whereas in cases with loosening of screws it was difficult to do so.

Keywords: Dynamic compression plate, Fracture, Humerus, Interlocking nail 


\section{INTRODUCTION}

Fractures of humeral shaft are commonly encountered by orthopaedic surgeons, accounting for approximately $3 \%$ of all fractures. ${ }^{1-3}$ Treatment of these injuries continues to evolve as advances are made in both operative and nonoperative management. ${ }^{4-5}$ Most humeral shaft fractures can be managed non-operatively with anticipated good to excellent results. ${ }^{6-7}$ The humeral shaft is totally covered with muscles and fracture fragments are well vascularised. Humeral shaft fractures result from direct and indirect trauma. Healing of the fracture like any other wound, depends upon blood supply. ${ }^{8-10}$ A study on the blood supply of adult humerus by injecting radio opaque contrast medium into the brachial artery of cadavers and taking radiographs was performed. ${ }^{11}$ The largest artery supplying the humerus is termed as the main nutrient artery. According to his study, the main nutrient artery arises in two third cases from the brachial artery and in the remaining cases from the profunda brachii artery. The point of entry of the main nutrient artery to the humerus is a restricted area, beginning on the medial side of the distal third and spiralling upwards and medially to the dorsal surface of the middle third of the shaft was proved by dissection in cadavers. ${ }^{12-13}$ The main nutrient artery on or before entering the bone divides into ascending and descending branches. The ascending branch travels up the medullary canal and anastomoses with accessory nutrient arteries and with periosteal vessels through trans cortical vessels. In most cases, a peculiar coiled arrangement of the beginning of the ascending branch was noted. ${ }^{14}$ Descending branches are usually smaller and divide immediately into branches to reach supracondylar region. Accessory nutrient arteries vary from one to four in number and may arise from anterior circumflex humeral artery or profunda brachii artery. These arteries enter the bone either in the spiral groove or in the anterolateral surface, mostly in the upper third of the shaft. If surgeons could avoid the area of cortex of the humerus containing the nutrient artery foramen during open reduction an improvement in the result might be expected. ${ }^{15}$ The danger of damaging the blood supply during operation is maximum in open reduction of fractures at the junction of middle and lower third. ${ }^{16}$ In such cases, upper end of lower fragment will depend on epicondylar vessels and periosteal stripping of the lower fragment should be avoided. Because of the intramedullary course of the nutrient artery, it may get damaged during intramedullary nailing and at the same time if periosteum is stripped extensively, blood supply will be jeopardized unduly. The critical neurovascular structures in surgery of the arm do not stay neatly in one operative field, but cross from compartment to compartment, as they course down the arm. ${ }^{17}$ Therefore, it is easiest to view the anatomy of the arm as consisting of two major muscle compartments, flexor and extensor, that share responsibility for three major nerves and arteries. Humeral shaft fractures result from direct and indirect trauma. In majority of case, they are the result of direct injury such as fall on the arm at the side or blows. It may result from indirect violence such as a fall on the elbow or hand. Extreme muscle contraction may cause fracture of the humerus. Pure compressive forces result in proximal or distal humerus fractures; bending forces, however, typically result in transverse fractures of the humerus shaft. Torsional forces result in spiral fracture patterns. The combination of bending and torsion usually results in an oblique fractures, often with an associated butterfly fragment. Greater amounts of comminution and soft tissue injury results from high energy injuries. Rarely there may not be any displacement. ${ }^{18}$ The muscle forces that act on the humeral shaft produce characteristic deformities. A fracture proximal to the pectoralis major insertion results in abduction and internal rotation of the proximal fragments secondary to the pull of rotator cuff, while the distal fragment is displaced medially by pectoralis major. If the fracture is distal to the pectoralis major insertion and proximal to the deltoid insertion, the distal fragment is laterally displaced by the deltoid, while the pectoralis major, latissimus dorsi and teres major displace the proximal fracture medially. When the fracture is distal to deltoid insertion, the proximal fragment is abducted and flexed while the distal fragment is proximally displaced. Patient with humeral shaft fracture presents with history of trauma, arm pain, swelling and deformity. The arm is shortened with gross motion, local tenderness and crepitus on gentle manipulation. Neuro vascular status of the extremity must be assessed. Identification of associated injuries and immediate management of life threatening injuries must be done. The standard X-ray views include anteroposterior and lateral views. The shoulder and elbow joint should be included in each view. The goals of humeral shaft fracture management are to establish union with acceptable humeral alignment and restore patients to their prior level of function. ${ }^{19-20}$

Many methods have been described for the management of humeral shaft fractures. Good to excellent results have been reported in most series of humeral shaft fractures treated closed or with open reduction and internal fixation. Both patient and fracture characteristics, associated injuries, soft tissue status and fracture pattern need to be considered to select appropriate treatment.

\section{METHODS}

This study was undertaken in the Department of Orthopaedics, Katihar Medical College, Katihar. Patients selected were admitted from either the outdoor clinic of the Department of Orthopaedics or the Emergency Department of this institute. Interlocking nailing was done only if the fracture was $>2 \mathrm{~cm}$ distal to surgical neck or $3 \mathrm{~cm}$ proximal to olecranon fossa. After selection, patients were subjected to routine history taking, clinical examination, pre-operative assessment followed by pre-operative and post-operative 
radiographic examinations. After diagnosing the cases as humeral shaft fractures, they were stabilized with the help of POP U-slab to prevent movement at fracture site and reduce pain. Any other associated injuries were treated accordingly. A day prior to operation, local shaving and antiseptic dressing with povidine iodine was done. Patients were given light meal in the previous night and 5 mg of diazepam tab at bedtime. Additional advices given by the anaesthetist were followed. General anaesthesia was given under full antiseptic and aseptic precautions.

\section{Operative technique for humeral interlocking nail}

The patients were laid supine and head turned to opposite side. Nail length and diameter were estimated preoperatively. In late displaced fractures, open reduction was required. Part was prepared and draped. A longitudinal skin incision was made from most lateral part of the acromion and extended distally centred over tip of greater tuberosity taking care not to extend the incision beyond $4-5 \mathrm{~cm}$ in deltoid to avoid damage to axillary nerve. The fascia of deltoid muscle was incised and the greater tuberosity was palpated.

Awling: Using a curved bone awl, an entry portal was made just medial to the tip of greater tuberosity approximately $0.5 \mathrm{~cm}$ posterior to bicipital grove (to minimize damage to rotator cuff). The humerus was manipulated and reduced for closed nailing.

Guide wire: A guide wire was advanced in medullary canal upto 1-2 cm proximal to olecranon fossa. Using a second guide wire, the length of nail to be inserted was measured.

Reaming: The canal was reamed for maximum diameter nail to be used.

Nail introduction: The nail was then seated to avoid subacromial impingement.

Distal locking: The distal locking was done using free hand technique using $3.5 \mathrm{~mm}$ screws from anterior to posterior. A 1-2 cm transverse incision was made over the slot of nail as seen on image intensifier and muscle spread using a haemostat. Trocar was placed over bone and a hole made over the distal slot by a $2.5 \mathrm{~mm}$ drill bit and confirmed with image intensifier.

Using the screw length gauge the length of screw was measured and selected screw passed into the hole by a humeral hexagonal screwdriver. Then the fracture site was impacted.

Proximal locking: The drill barrel was passed through the proximal drill guide along with the trocar and where the skin was dimpled by the trocar, a small incision was made and the trocar passed upto bone. The trocar was exchanged for a drill sleeve and using $3.2 \mathrm{~mm}$ drill bit, the proximal screw hole drilled from lateral to medial cortex while keeping the arm abducted to avoid damage to the brachial artery. The screw depth gauge was then inserted through the drill barrel and the required bolt length estimated. The appropriate sized bolt was selected and inserted with a hexagonal screw driver.

\section{RESULTS}

\section{Operative technique for dynamic compression plating}

Operative stabilization of humeral shaft fractures may be performed through an anterior, posterior or anterolateral approach.

\section{Anterior approach}

The anterior approach to the humeral shaft is similar to the anterolateral approach. It cannot be extended distally however, to the elbow. The patient was positioned supine. A longitudinal incision was made from the coracoid process to the deltoid insertion and extended distally following the lateral border of the biceps. The distal limit of the incision was $5 \mathrm{~cm}$ proximal to the elbow flexion crease. The brachialis and the biceps muscle interval was identified and the biceps retracted medially. The fibres of brachialis were separated longitudinally to expose the anterior surface of the humeral shaft. The periosteum lateral to the pectoralis major insertion was incised and the humerus subperiosteally dissected. The approach was kept subperiosteal to avoid radial nerve injury. Since this approach cannot be extended distally, it is less useful than the anterolateral approach to the humerus.

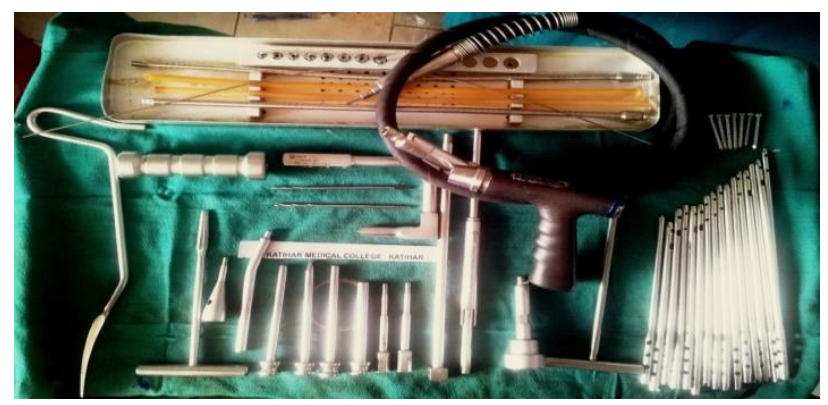

Figure 1: Instruments required for interlocking nailing of humeral shaft.

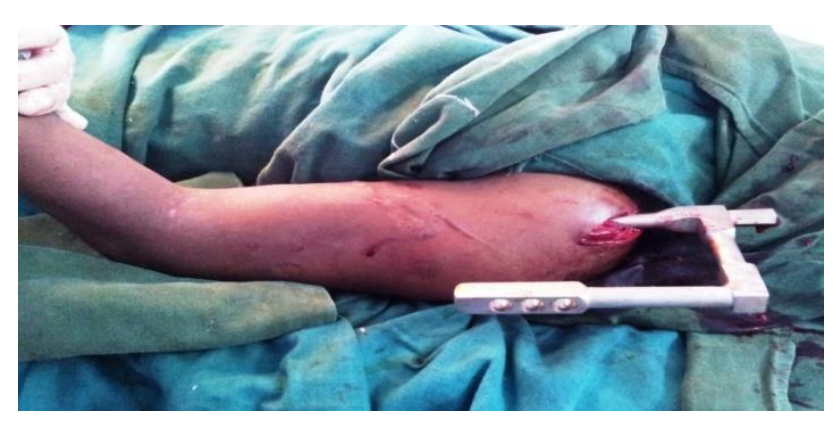

Figure 2: Introduction of nail in humeral shaft for interlocking nailing. 


\section{Posterior approach}

The posterior approach provides excellent exposure to most of the humerus and is limited only in its most proximal extent. The patient was positioned either lateral or prone. A posterior longitudinal incision extends from 8 $\mathrm{cm}$ distal to the acromion to the olecranon. The interval between the lateral and long heads of the triceps was identified and these two muscles separated. The medial head of the triceps was identified; radial nerve lies alongside its lateral border and was traced proximal and distal through the intermuscular septum. The medial head of the triceps was incised longitudinally and the posterior aspect of the humerus subperiosteally dissected. Proximal dissection is limited by the axillary nerve and posterior humeral circumflex vessels. At surgery, minimal stripping of soft tissues was performed; butterfly fragments were not devitalized. $4.5 \mathrm{~mm}$ dynamic compression plates were selected for shaft fractures in average to large sized patients. In smaller patients, a $4.5 \mathrm{~mm}$ narrow dynamic compression plate was used. Lag screws were inserted wherever required. Fixation of eight to ten cortices proximal and distal to the fracture was obtained.

\section{Anterolateral approach}

The patient was positioned supine with the arm placed either on a hand table or arm board. An incision was made along the lateral border of the biceps, ending just proximal to the elbow flexion crease. The lateral border of the biceps was identified and the muscle retracted medially. The interval between the brachialis and brachioradialis was identified proximal to the elbow and the two muscles separated. The brachioradialis was retracted laterally and the brachialis and biceps muscles retracted medially. The radial nerve was identified. The radial nerve was traced proximally through the lateral intermuscular septum and protected throughout the remainder of the procedure. The periosteum was incised longitudinally at the lateral border of the brachialis muscle and the humerus subperiosteally dissected. This approach is preferred for proximal third humerus fractures.

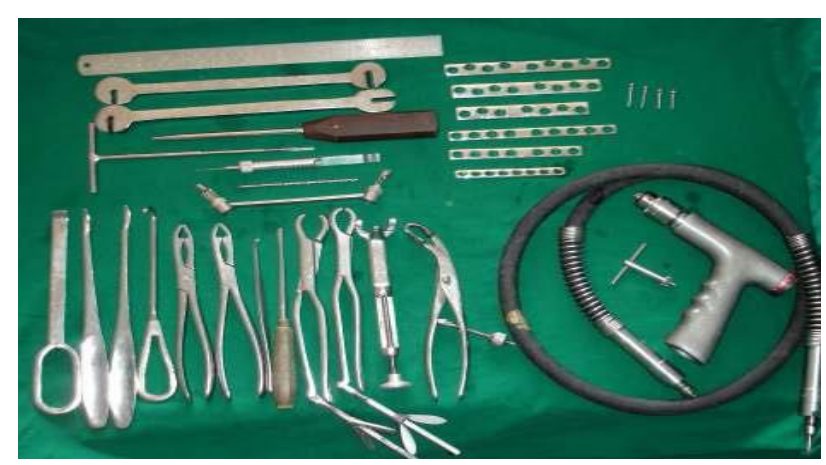

Figure 3: Instruments required for dynamic compression plating.

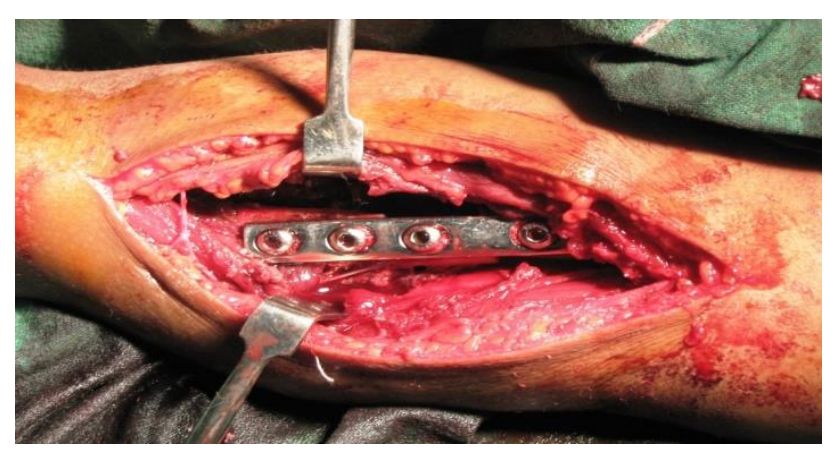

Figure 4: Dynamic compression plate.

\section{Our observations were as follows:}

\section{Age distribution}

The youngest patient was 20 years old and the oldest was 73 years old. 3 patients were lost in follow-up, so the total number of patients evaluated was 26. Most of the patients in either group were of the age 20-50 years.

Table 1: Age distribution among cases in both groups.

\begin{tabular}{|lll|}
\hline $\begin{array}{l}\text { Age } \\
\text { (In years) }\end{array}$ & $\begin{array}{l}\text { Group-A } \\
\text { (Interlocking Nail) }\end{array}$ & $\begin{array}{l}\text { Group-B } \\
\text { (Dynamic } \\
\text { Compression Plate) }\end{array}$ \\
\hline $20-30$ & $5(33.3 \%)$ & $6(42.8 \%)$ \\
\hline $31-40$ & $3(20.0 \%)$ & $4\left(5^{-} 5 \%\right)$ \\
\hline $41-50$ & $5(33.3 \%)$ & $2(14.3 \%)$ \\
\hline $51-60$ & $1(6.7 \%)$ & $2(14.3 \%)$ \\
\hline $61-70$ & - & - \\
\hline$>70$ & $1(6.7 \%)$ & - \\
\hline Total & $15(100 \%)$ & $14(100 \%)$ \\
\hline
\end{tabular}

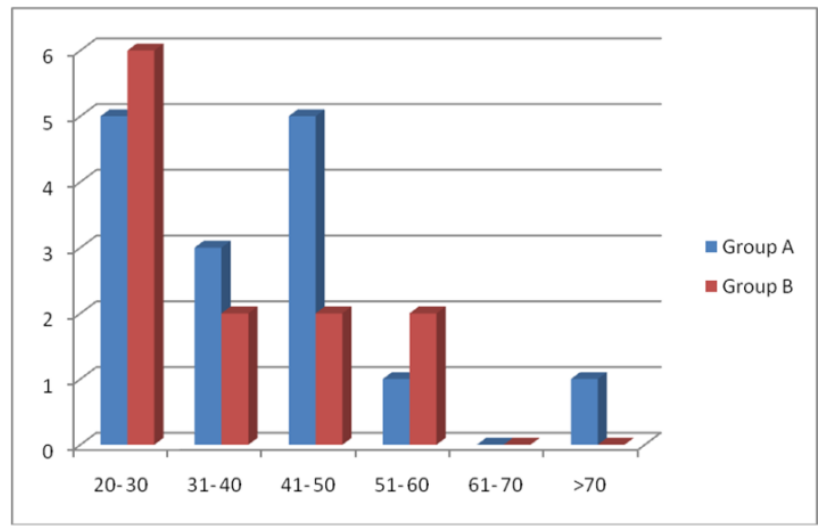

Figure 5: Age distribution among cases in both groups.

Mean age: The mean age of group-A was found to be 37.1 years as compared to 34.7 years in group-B. The difference in age group is statistically insignificant as the patients were randomly selected. 
Sex distribution: In group-A, 14 patients (93.3\%) were male and 1 patient $(6.7 \%)$ was female while in group-B, 12 patients $(85 \%)$ were male and 2 patients $(14.3 \%)$ were female. More number of males in our study can be attributed to the fact that in our society males are predominantly outside workers and so, are more commonly involved in road traffic accidents.

Mode of injury: 11 patients of group-A (73.3\%) and 8 patients of group-B (57.2\%) sustained trauma in road traffic accidents; 3 patients in group-A $(20 \%)$ and 5 patients in group-B $(35.7 \%)$ sustained trauma as a result of fall on ground. One patient in group-A $(6.7 \%)$ sustained injury as a result of assault by lathi and one of group-B $(7.1 \%)$ because of hand getting caught in an electric machine.

Table 2: Mode of injury among cases in both groups.

\begin{tabular}{|lll|}
\hline Mode of injury & Group A & Group B \\
\hline Road traffic accident & $11(73.3 \%)$ & $8(57.2 \%)$ \\
\hline Fall on ground & $3(20 \%)$ & $5(35.7 \%)$ \\
\hline Hit by Lathi & $1(6.7 \%)$ & - \\
\hline Occupational hazard & - & $1(7.1 \%)$ \\
\hline Total & $15(100 \%)$ & $14(100 \%)$ \\
\hline
\end{tabular}

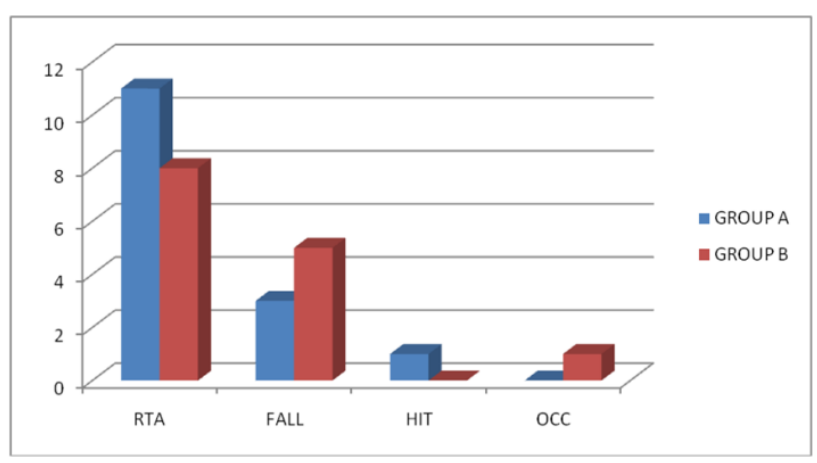

RTA - road traffic accidents, FALL - fall on ground, HIT hit by lathi, OCC - occupational hazards.

Figure 6: Distribution of modes of ijury among cases in both groups.

Duration of injury: Most of the cases of either group were more than 7 days old because initial management of fracture shaft of humerus was tried conservatively. If the conservative management failed then the patient was put up for operative management. 4 cases of established nonunion were taken up for humerus interlocking and 1 case for Dynamic Compression Plating.

Average duration between trauma and fixation: Humeral interlocking was done in neglected cases where the average duration between trauma and fixation was 4.7 months while dynamic compression plating was done relatively earlier in 2.1 months.
Evaluation of elbow movement at 12 weeks: There were 13 patients in follow-up available in group-A and 13 in group-B. 12 patients of group-A $(92.2 \%)$ and 11 patients of group-B $(84.6 \%)$ had full range of motion at elbow. Loss of extension of $<30 \mathrm{o}$ was seen in 1 patient of groupA $(7.7 \%)$ and 2 patients of group-B (7.7\%). 1 patient of each group with $<30$ o of elbow restriction were those in which the procedure had lead to non-union and were on prolonged immobilization rather than early mobilization. The patient of Group-B having > 30o loss of both flexion and extension was the one where the fracture was in the distal one-third for which DCP had been previously done and non-union had occurred after trauma. The patient was managed by removal of DCP and reapplication of DCP with bone grafting and the plate extended much distally. Though the elbow movements were restricted, union was achieved.

Range of elbow joint movements at 12 weeks: Though 1 patient lost terminal degree of flexion as a result of nonunion, the average range of movements at elbow were improved. This was as a result of physiotherapy and early mobilization of the patients postoperatively. Preoperatively patients did not have a full range of motions as many patients had non-union. In patients who underwent dynamic compression plating, the average range of movements of elbow was not significantly altered because the patients could not be fully mobilized as well as their interlocking counterparts.

Table 3: Pre-op \& post-op range of elbow joint movements in both groups.

\begin{tabular}{|lll|}
\hline $\begin{array}{l}\text { Range } \\
\text { (In degrees) }\end{array}$ & $\begin{array}{l}\text { Group-A } \\
\text { (Interlocking } \\
\text { Nail) }\end{array}$ & $\begin{array}{l}\text { Group-B } \\
\text { (Dynamic } \\
\text { Compression Plate) }\end{array}$ \\
\hline Pre-op & $7^{\circ}-130^{\circ}$ & $4^{\circ}-130^{\circ}$ \\
\hline Post-op & $3^{\circ}-134^{\circ}$ & $5^{\circ}-130^{\circ}$ \\
\hline
\end{tabular}

Table 4: Percentage of union/non-union among cases in both groups.

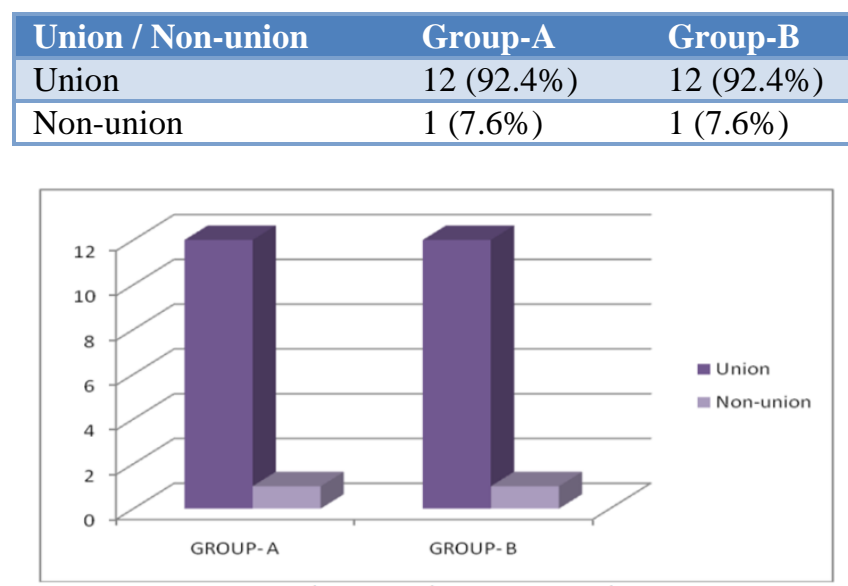

Figure 7: Percentage of union/non-union among cases in both groups. 
Evaluation of shoulder movement at 12 weeks: 13 patients of group-A and 13 of Group-B were available for follow up. Shoulder movements were restricted in terminal degrees of movements somewhat more in groupA patients as compared to patients of Group-B. This may be because of the entry portal that is made at the shoulder that disturbs the rotator cuff healing due to some fibrosis leading to restriction of movements at the terminal degrees. Also, in some patients, the proximal end of the nail impinges on the rotator cuff when not properly buried inside the bone.

Union time (bridging callus and absence of clinical tenderness): Out of 13 patients available for follow up in group-A and 13 in group-B, 12 united in group-A and 12 in Group-B. Patients of Group-A had an average union time of 6.2 weeks as against 8.8 weeks in group-B. This is a significant difference in union time between the two groups, in both groups it was observed that union time was lesser in patients where bone grafting was also done along with internal fixation.

Percentage union: The union rate of either group in this study was found to be identical and so was the non-union rate. The non-union that developed in each group were the patients who were already in delayed union or frank non-union. The patient of group A who developed nonunion, was managed by removal of KIM nail, open reduction and internal fixation by a humeral interlocking nail and addition of formalized allograft; but the patient developed deep-seated infection with persistent discharging sinus and subsequently developed non-union. The non-union in group B was managed by dynamic compression plating but developed implant failure and loosening of screws and ultimately did not unite.

Complications: 4 patients of group B (30.8\%) managed by dynamic compression plating developed infections. Two of them were superficial infections that responded well to antibiotics and dressings and later healed well and united. Two patients developed discharging sinuses and subsequently infected union. Later the plate was removed and sinus tract excised. The sinus tract healed but left unsightly scar marks over the arm. Only one patient (7.7\%) of group A developed deep-seated infection and subsequent non-union. 3 patients of group A (23.1\%) developed shortening ranging from $1.5 \mathrm{~cm}$ to $4 \mathrm{~cm}$. All of these patients were old non-unions with sclerotic bone ends which had to be nibbled and refreshened. Shortening developed in 2 patients $(15.4 \%)$ of group B. One nonunion was seen in each group. While the screws of one dynamic compression plating (7.7\%) went loose, no implant failure occurred in interlocking nails. One patient (7.7\%) of group-A developed axillary nerve injury, which might be attributed to the fact that the incision extended $6-7 \mathrm{~cm}$ beyond the acromion process. Only one patient developed $10^{\circ}$ angulation and that belonged to group $\mathrm{B}$.

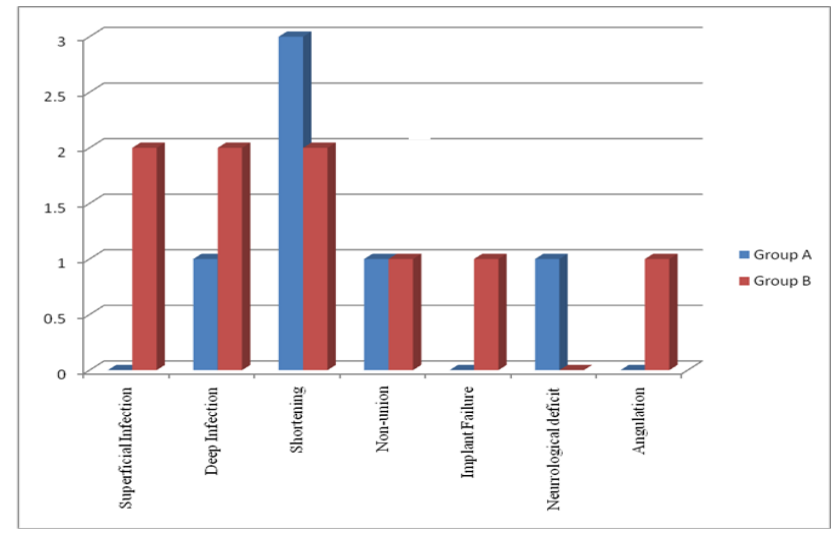

Figure 8: Distribution of complications among cases in both groups.

Functional results: All patients, except one from each group returned to their previous jobs. Both these patients developed non-union. They were able to do day to day activities but not able to join their previous jobs. Thus, the functional result was good in $92.3 \%$ of patients and poor in $7.7 \%$ of patients of either group. An advantage of humerus interlocking was that, even when the patient developed non-union, he was able to perform daily activities but the patient with loosening of screws found it difficult to do so.

\section{DISCUSSION}

The aim of operative reduction and internal fixation of fracture of humerus is to attain and maintain a stable reduction so as to mobilize the patient's limb in the shortest possible time and that the fracture healing is ensured. ${ }^{21-23}$ Dynamic compression plating has stood the test of time as an excellent method of stabilizing transverse diaphyseal fractures of humerus. ${ }^{24-25}$ The plate produces a compression at the fracture site promoting osteosynthesis. ${ }^{26}$ But the technique is not suitable for segmental fractures, pathological fractures, communited fractures, gross osteoporosis, non-union and fractures much proximal or distal to shaft. Introduction of interlocking nailing has largely solved problems faced by the standard dynamic compression plating. ${ }^{27-29}$ The advantages of a stable reduction maintained by a humeral interlocking nail must be weighed against the technical problems and the need for prolonged fluoroscopy to target the distal holes. ${ }^{30-32}$ We treated a total of twenty nine patients in the Department of Orthopaedics. Fifteen patients were treated by internal fixation by humerus interlocking nail (group A) and 14 patients were treated by dynamic compression plating (group B). Two patients of Group A and one patient of Group B were lost in follow-up. The majorities of patients in both groups was males (93.3\% males in group-A and $85.7 \%$ in group-B) and were in the age group of $20-50$ years $(86.6 \%$ of group-A and $85.7 \%$ of group-B). Most of the patients sustained trauma as a result of road traffic accidents (73.3\% in group-A and $57.2 \%$ in group-B). Fifteen patients were treated by antegrade humeral interlocking 
out of which two were lost in follow-up. The average time of clinico-radiological union (absence of bony tenderness clinically and presence of bridging callus on $\mathrm{X}$-ray) was 6.2 weeks. Shoulder problems: In Group A of this present study, restriction of $>30^{\circ}$ abduction was seen in $7.7 \%$; restriction of $>30^{\circ}$ adduction in $7.7 \%$; restriction of $>30^{\circ}$ flexion in $7.7 \%$; restriction of $>30^{\circ}$ extension in $7.7 \%$; restriction of $>30^{\circ}$ internal rotation in $7.7 \%$ and restriction of $>30^{\circ}$ external rotation in $23.1 \%$ of cases. There was no implant failure. Implant failure leading to re-operation was required in $16 \%$ cases. Shortening was seen in 3 patients. All these cases were of established non-union where the fracture ends were sclerotic and atrophic and nibbling of bone ends had to be done. No case of nail migration was seen. In 5 patients of interlocking nail good callus was seen as early as 3-4 weeks. Fourteen patients were treated by dynamic compression plating of which one was lost in follow up. The average time of clinico-radiological union was 8.8 weeks. There were 4 infections $(30.76 \%)$. The infection rate observed in dynamic compression plate as compared to interlocking humerus was significantly high. One implant failure was seen. Shortening was seen in 2 patients which were cases of non-union. The bone ends were sclerotic and nibbling of bone ends was required. Bridging callus was actually not visible in all patients but partial obliteration of fracture site and loss of tenderness was seen at an average of 8.8 weeks. Shoulder and elbow functions were satisfactory.

\section{CONCLUSION}

Early mobilization generally hastens union by allowing the hydrodynamic forces of muscle activity to enhance local blood supply and encourage the organization of healing granuloma by allowing stress forces to function. Though the patients of dynamic compression plating have a better shoulder function than the patients undergoing antegrade humeral interlocking, it is to some degree due to uncooperative patients, pain and impingement of rotator cuff by nail and fibrosis. But this restriction can be corrected by the removal of nail after consolidation followed by mobilization and physiotherapy. Humeral interlocking nailing as compared to dynamic compression plating is complicated as well as exacting in detail. Specialized costly equipments (high quality image intensifier, modern flexible drills, nail insertion and targeting devices) are necessary and no compromise in that respect is permitted if this operation is to be successful. But the advantage of the procedure is definitely that the rate of infection is low when compared. In dynamic compression plating, stripping of soft tissues and periosteum leads to an increase in union time as compared to interlocking nail. The disadvantages of humeral interlocking may be limited to mild restriction of shoulder movements which is correctable by removal of the nail after consolidation of the fracture. The advantages of interlocking of diaphyseal fractures of shaft of humerus are early union, minimal exposure of soft tissues, less blood loss, minimal scarring and so a cosmetically better procedure. Moreover, it is ideal for patients with segmental fractures, communited fractures, pathological fractures, and patients with gross osteoporosis, patients in which Dynamic Compression Plating cannot be done, distal end fractures and implant failures. There is less chance of radial nerve damage and the patient undergoes early mobilization. The removal of the implant is much easier than removal of dynamic compression plate and associated with less blood loss and lesser chances of nerve injury (due to nerve being caught in fibrosis). Also, after removal of dynamic compression plating there are more numbers of stress risers created that may lead to re-fracture.

\section{Funding: No funding sources}

Conflict of interest: None declared

Ethical approval: The study was approved by the Institutional Ethics Committee (IEC) of Katihar Medical College as the author was previously a Junior Resident in the Department of Orthopaedics of Katihar Medical College, Katihar, Bihar, India

\section{REFERENCES}

1. Laing PG. The arterial supply of the adult Humerus. J Bone Joint Surg. 1956;38:1105-16.

2. Carrol SE. A study of the nutrient foramina of the humeral diaphysis. J Bone Joint Surg. 1956;38:1105-16.

3. Klenerman L. Fractures of shaft of the humerus. $\mathbf{J}$ Bone Joint Surg. 1966;48:105-11.

4. Bailfour GW, Mooney V, Ashby ME. Diaphyseal fractures of the humerus treated with a readymade fracture brace. J Bone Joint Surg. 1982;64:11-3.

5. Brumback RJ, Bose MJ, Poka A, Burgess AR. Intramedullary stabilisation of humerus shaft fractures in patients with multiple trauma. J Bone Joint Surg. 1986;68:960-70.

6. Mast JW, Spiegel PG, Harvey JP, Harrison C. Fractures of the humeral shaft. Clin Orthop. 1975;12:254-62.

7. Sarmiento A, Kinman P, Galvin E. Functional bracing of fractures of the shaft of the humerus. J Bone Joint Surg. 1977;59:596-601.

8. Stewart MJ, Hundley JM. Fracture of the humerus: A comparative study in methods of treatment. J Bone Joint Surg. 1955;37:681-39.

9. Bhalla R, Narang TS, Lobo LH. Functional brace treatment of the fracture of the shaft of the humerus. Ind J of Orthop. 1982;1(6):25-8.

10. Bhandari M, Devereaux PJ, McKee MD. Compression plating versus intramedullary nailing of humeral shaft fractures-a meta-analysis. Acta Orthop. 2006;77:279.

11. Ivan RF, Peter K. Open reduction and internal fixation of humeral non-unions. J Bone Joint Surg. 2002;84(8):1315-22.

12. Liang HT. Treatment of non-union of humeral shaft fracture with dynamic compression plate and 
cancellous bone graft. J Chin Med Assoc. 2005;68(2):73-6.

13. McKee MD. Fractures of the shaft of the humerus. In: Bucholz RW, Heckman JD, Court-Brown CM eds. Rockwood and green's fractures in adults. Philadelphia, Lippincott Williams and Wilkins; 2006.

14. Lin J, Hou SM. Treatment of humeral shaft delayed unions and non-unions with humeral locked nails. J Trauma. 2000;48:695-703.

15. Dijkstra $\mathrm{S}$, Wiggers $\mathrm{T}$, Boxma H. Impending and actual pathologic fractures in patients with bone metastasis of the long bones. A retrospective study of 233 surgically treated fractures. Eur J Surg. 1994;160:535-42.

16. Tom EJ, Carsi D, Garcia C, Marco F. Treatment of pathologic fractures of the humerus with seidel nailing. Clin Orthop. 1998;350:51-5.

17. Damron TA, Rock MG, Choudhary SN, Grabowski JJ. Biomechanical analysis of prophylactic fixation for middle third humeral impending pathological fractures. Clin Orthop. 1999;363:240-8.

18. Dabezeis EJ, Banta CJ, Murphy CP, Ambrosia RD. Plate fixation of the humeral shaft for acute fractures with and without radial nerve injuries. J Orthop Trauma. 1992;6(1):10-3.

19. Wright TW, Miller GJ. Reconstruction of the humerus with an intramedullary fibular graft. J Bone Joint Surg. 1993;75:804-7.

20. Habernek H, Schrmid Z, Orthner E. Initial experiences with humerus interlocking nail. Unfall Chirurgie. 1992;18(4):233-7.

21. Guse TR, Ostrum RF. The surgical anatomy of the radial nerve around the humerus. Clin Orthop Relat Res. 1992;320:149-53.

22. Strong GT. The epidemiology of humeral shaft fractures. J Bone Joint Surg. 1998;80:249-53.

23. Chapman JR, Bradford HM. Randomized prospective study of humeral shaft fracture fixation: intramedullary nails versus plates. J Orthop Trauma. 2000;14:162-6.

24. McCormack RG, Brien D, Buckley RE, McKee MD. Fixation of fracture of the shaft of humerus by dynamic compression plate or intramedullary nail. J Bone Joint Surg. 2000;82:336-9.

25. Gupta R, Raheja A, Sharma V. Limited contact dynamic compression in diaphyseal fractures of the humerus. Acta Orthop Scand. 2000;71:471-4.

26. Sarmiento A, Jagorski JB, Zych GA. Functional bracing for the treatment of the fractures of humeral diaphysis. J Bone Joint Surg. 2000;82:478-86.

27. Koch PP, Gross DF, Gerber C. The results of functional bracing of humeral shaft fractures. J Shoulder Elbow Surg. 2002;11:143-50.

28. Sarmiento A, Latta LL. Conservative treatment of humeral shaft fractures. Unfallchirug. German Trauma Assoc. 2007;110:824-32.

29. Paris H, Tropiano P, Clouet B, Chaudet H, Poitout DG. Fractures of the shaft of humerus: systemic plate fixation. J Bone Joint Surg. 2000;82:336-9.

30. Ajmal M, McCabe J. Antegrade locked intramedullary nailing in humeral shaft fractures. Injury. 2001;32:692-4.

31. Flinkkila T, Hyvonen P, Siira P, Hamalainen M. Recovery of shoulder joint function after humeral shaft fracture: a comparative study between antegrade intramedullary nailing and plate fixation. Arch Orthop Trauma Surg. 2004;124:537-41.

32. Kesemenli CC, Subasi M, Arslan H, Necmioqlu, Kapukaya A. Comparison between nailing and compression plating of humerus fractures. Acta Orthop Trauma Turc. 2003;37(2):120-5.

Cite this article as: Hashib G. Management of humeral shaft fracture: a comparative study between interlocking nail and dynamic compression plate. Int $\mathbf{J}$ Res Orthop 2016;2:40-7. 